\title{
A Molecular Approach for the Detection and Quantification of Tribolium castaneum (Herbst) Infestation in Stored Wheat Flour
}

Aditi Negi ${ }^{1,2} \odot$, Arunkumar Anandharaj $j^{3^{*}}$, Sureshkumar Kalakandan and Meenatchi Rajamani ${ }^{1 *} \odot$

'Department of Primary Processing, Storage and Handling, Indian Institute of Food Processing Technology, 613005 Thanjavur, Tamil Nadu, India

²Bharathidasan University, 620024 Tiruchirappalli, Tamil Nadu, India ${ }^{3}$ Department of Food Safety and Quality Testing, Indian Institute of Food Processing Technology, 613005 Thanjavur, Tamil Nadu, India

Received: 20 July 2020 Accepted: 4 March 2021

*Corresponding authors:

Phone: +919940058889

Fax: +914362227971

E-mail: arunkumar@iifpt.edu.in

Phone: +919750968420

E-mail: meena@iifpt.edu.in

\section{SUMMARY}

Research background. The presence of insect fragments is one of the major constraints in stored food commodities and it causes considerable loss in the quality of the produce. The management of the pest is viewed as a huge challenge in foodprocessing industry. Conventionally, the detection of Tribolium castenaum in the food processing industry is carried out by acid hydrolysis and staining methods that are time consuming and lack precision.

Experimental approach. Considering the importance of a quick and effective method, a quantitative real-time polymerase chain reaction (qRT-PCR)-based approach was developed and elucidated in this study. The mitochondrial cytochrome oxidase I ( $m t C O l)$ gene was identified as a target due to its abundance in the pest. Specific primers were designed against the target gene by Primer Premier software for amplification in qPCR.

Results and conclusions. This method is capable of detecting all the ontogenic stages of $T$. castaneum in stored wheat flour. Earlier experiments had demonstrated that about $20 \mu \mathrm{g}$ of DNA can be obtained from $2.2 \mathrm{mg}$ of insects. To quantify the infestation levels, the cycle threshold $(\mathrm{Ct})$ values obtained from known samples were subjected to regression analysis and expressed as adult equivalents. In the unknown samples, the infestation was calculated as 1.74 and 0.046 adult insects in $5 \mathrm{~g}$ of wheat flour. The maximum permissible limit of insect fragments in flour is 75 insect fragments or approx. 3 adults in $50 \mathrm{~g}$ of flour as per the US Food and Drug Administration (FDA). Hence, by adopting this new method, it is possible for the warehouse operators to arrive at a decision to proceed with efficient management practices where wheat flour is stored. Also, this method can be ratified by government agencies associated with international business to ascertain whether the wheat flour meets the standards set by the respective country before subjecting to foreign trade.

Novelty and scientific contribution. This study is the first of its kind in the detection and quantification of $T$. castaneum in milled products. So far, only conventional methods have been employed to assess the presence of the pests and manual counting of fragments is practiced to quantify the infestation levels. The developed qRT-PCR method is faster, more reliable and can be employed in milling industries, bakery industries, food processing plants and foreign trade units for critical detection and quantification of T. castaneum pest infestation.

Key words: insect detection, wheat flour, Tribolium castaneum, qRT-PCR, red flour beetle

\section{INTRODUCTION}

Wheat is one of the major cereal crops cultivated in India and its production has reached an all-time high of 99.70 million tonnes in 2019 (1). Globally, India ranks second in the production of wheat, despite the total postharvest losses of about $33.5 \%$ in stored wheat and wheat flour (2). The major issue is the presence of insects, which is responsible for 5-15\% loss during storage (3). Tribolium castaneum (red flour beetle) is one of the major pests infesting wheat flour during post harvest processing. Even when high standards of sanitary and handling procedures are practiced, the flour is susceptible to infestation by pests (4). 
The adults of $T$. castaneum are long living, often up to 3 years and undergo complete metamorphosis during their life cycle. The female insect lays up to 300-500 eggs during her life span. Complete life cycle of the insect ranges from 7 to 12 weeks depending on temperature $\left(35^{\circ} \mathrm{C}\right)$ and relative humidity (60-80\%) (5). Larva and adults are the active feeding stages of T. castaneum and cause significant damage to food commodities. During postharvest handling and storage, the grain seeds are often broken or wounded by other internal feeders, which makes it easier for the red flour beetle to infest them (6). The pest infestation causes severe damage to the products, like contamination with faeces (mainly uric acid), which increases the humidity of the flour, promoting hot spots for fungal or mould growth. Besides the contamination with the body fragments and frass, the flour is also exposed to quinones that are secreted by the adult insects as a defence mechanism (7). These quinones are responsible for the unpleasant odour and are known to induce liver and spleen tumours, when tested in rats and other vertebrates $(8,9)$. The quinones also affect humans by causing several complications like jaundice, anaemia, allergic responses, etc. The product quality and marketability of the flour is greatly reduced due to the infestation, resulting in the huge economic loss.

In the food industry, the quality and integrity are considered as important criteria for the successful export/import of any produce in the market. The insects present in the broken wheat are crushed during milling and thereby the fragments are blended to the flour and ultimately affect the quality of the flour. In European countries, there is no systematic surveillance or any scientific risk assessment programs on storage of pests, albeit a zero or nil tolerance for insect or insect fragments has been established in food and food products $(10,11)$. In the USA, the Food and Drug Administration (FDA) has a defect action level of 75 insect fragments per $50 \mathrm{~g}$ of wheat flour (12), whereas in Canada the defect action level should not exceed more than 25 fragments per $50 \mathrm{~g}$ of flour (13).

Currently, various techniques employed to detect insects and their fragments in stored food commodities are based on: (i) sieving, (ii) physical examination, (iii) microscopic methods such as staining and acid hydrolysis, (iv) enzyme-linked immunosorbent assay (ELISA) $(14,15),(v)$ near infrared spectroscopy (NIR) (16), (vi) filth flotation (17), and (vii) soft $\mathrm{X}$-rays (18-22). Although some of these methods are effective for detecting a particular stage of $T$. castaneum during infestation, yet none of these can detect all the developmental stages of the insect. Notably, detection of T. castaneum at initial stages of its life cycle is difficult. Due to stringent regulations followed by the government during import and export, it is imperative that the flour should be devoid of any insect or insect fragments before it is allowed to foreign trade. Hence, there is an urgent need to develop a new method to detect and quantify T. castaneum infestation at all ontogenic stages present in wheat flour. To the best of our knowledge, no study has been conducted utilizing qRT-PCR for identifying insect infestation in stored wheat flour. This is the first study of its kind to use a qPCR technique that specifically amplifies a portion of $m t C O I$ (mitochondrial cytochrome oxidase) gene to successfully check and assess T. castaneum infestation in stored flour.

\section{MATERIALS AND METHODS}

\section{Insect specimen collection and rearing}

Major stored grain pests, namely Tribolium castaneum, Sitophilus oryzae and Lasioderma serricorne cultures, were maintained at Indian Institute of Food Processing Technology (IIFPT), Primary Processing, Storage and Handling Laboratory, Thanjavur, India. The cultures of $S$. oryzae were maintained on whole wheat and T. castaneum and L. serricorne in wheat flour at $30^{\circ} \mathrm{C}$ and $70 \%$ relative humidity $(\mathrm{RH})$. All stages of the insect development, viz. egg, larva, pupa and adults were maintained separately for the experimental study.

\section{Staining of T. castaneum eggs and fragments}

The T. castaneum eggs were stained with iodine as per the standard procedure described in AACC method 28-44.01 (23). About $50 \mathrm{~g}$ of $T$. castaneum-infested wheat flour was mixed with $500 \mathrm{~mL}$ of $5 \% \mathrm{HCl}$ (Hi-Media, Nashik, India) and light mineral oil. The sample was boiled for 10 min with constant stirring to ensure complete digestion. The digested sample was transferred to a separating funnel and allowed to stand at room temperature until phase separation was clearly visible. The lower layer was drained off leaving about $2.5 \mathrm{~cm}$ of the interface. The sample was then washed three times with hot water, followed by phase separation in a separating funnel. After the final wash, the sample was filtered through a lined filter paper and examined according to AACC method 28-41.03 (24) under a microscope (Leica StereoZoom S8 APO with LAS (Leica Application Suite) software v. 3.8.4; Leica, Singapore). The insect fragments present were counted and photographed.

\section{Insect DNA extraction procedures}

About $30 \mathrm{mg}$ of T. castaneum (egg, larva, pupa and adults) and adults of $L$. serricorne and $S$. oryzae were ground in liquid nitrogen using a clean glass rod to make a fine powder. DNA from egg, larva, pupa and adults was isolated using HiPurA ${ }^{\mathrm{TM}}$ (insect DNA purification kit MB529; Hi-Media) as per manufacturer's instructions. Finally, the total DNA was eluted in $200 \mu \mathrm{L}$ of elution buffer ( $10 \mathrm{mM}$ Tris- $\mathrm{Cl}, \mathrm{pH}=8.5$ ) by brief centrifugation (Centric 200R; Tehtnica, Železniki, Slovenia) at $16128 \times g$. Efficiency and integrity of the isolated DNA were checked by agarose gel electrophoresis and the purity was analyzed spectrophotometrically (UV 1800; Shimadzu, Sapporo, Japan) by measuring the absorbance at $\lambda_{260 \mathrm{~nm}}$ and $\lambda_{280 \mathrm{~nm}}$. The extracted DNA was stored at $-20^{\circ} \mathrm{C}$ until use for experiments. 


\section{Wheat DNA isolation}

Wheat grains purchased from the market were screened to ensure that there was no visible infestation. About $5 \mathrm{~g}$ of wheat grains were finely ground with a mortar and pestle and the powder was suspended in extraction buffer $(100 \mathrm{mM}$ Tris(hydroxymethyl) aminomethane (Tris)- $\mathrm{HCl}(\mathrm{pH}=8.0), 50 \mathrm{mM}$ EDTA ( $\mathrm{pH}=8.0$ ), $500 \mathrm{mM} \mathrm{NaCl}, 1 \%$ sodium dodecyl sulphate $(\mathrm{m} / \mathrm{V})$; Hi-Media) and vortexed for a few minutes. The contents were allowed to settle and $3 \mathrm{M}$ potassium acetate at $\mathrm{pH}=5.2$ (Hi-Media) was added, then the whole solution was vortexed and centrifuged (Centric 200R; Tehtnica) at 15 700×g for $10 \mathrm{~min}$. The upper layer was aspirated and approx. $350 \mu \mathrm{L}$ of prechilled isopropanol were added to the sample, which was then incubated at $-20^{\circ} \mathrm{C}$. The pelleted DNA was centrifuged and the supernatant was discarded, followed by washing of the pellet with ethanol twice and air dried. The pellet was dissolved in $100 \mu \mathrm{L}$ of Tris and EDTA (TE) buffer and analyzed by agarose gel electrophoresis (Bio-Rad, Irvine, CA, USA) for consistency.

\section{Designing the primer sequence and specificity analysis}

Specific primers were designed using Primer Premier 6 software available online (25) to target T. castaneum mitochondrial cytochrome oxidase I ( $m+\mathrm{CO}$ ) gene (GenBank (26) accession number EU048277.1) and synthesised by Eurofins Genomics India Pvt. Ltd., Bangalore, India. Multiple sequence alignment was performed using Gene Runner program v. 6.5.52 Beta (27) and a comparison of $m t C O I$ gene among $T$. castaneum, L. serricorne and S. oryzae was done to ensure the designed primers do not overlap with genes of other storage pests.

\section{Internal control/reference gene}

The $\mathrm{Ct}$ values of the target gene were normalized with $\mathrm{Ct}$ values of an internal control or reference gene. Here we used T. castaneum glyceraldehyde 3-phosphate dehydrogenase (GAPDH) gene, GenBank (26) accession number XM_969088, as a reference for this study. The primer sequence for GAPDH gene used in the study is 5'-GGACGCCTACGACCCTTCAG-3' and 5'-GTCATCAACCCCTCCACAATCT-3' for leading and lagging strands respectively (28) and the primer sequences were synthesised by Eurofins Genomics India Pvt. Ltd., Bangalore, India.

\section{$P C R$ reaction}

PCR amplification (Veriti ${ }^{\mathrm{TM}}$ 96-well thermal cycler; Applied Biosystems, Foster City, CA, USA) was performed in a reaction volume of $20 \mu \mathrm{L}$, containing $10 \mu \mathrm{L}$ of $2 X$ Master Mix (Aura, Chennai, India), $0.2 \mu \mathrm{M}$ of forward and reverse primers and the $100 \mathrm{ng} /$ reaction of template DNA $(29,30)$. The PCR conditions used for the amplification were as follows: initial denaturation at $95^{\circ} \mathrm{C}$ for $10 \mathrm{~min}$, followed by 40 cycles consisting of denaturation at $95^{\circ} \mathrm{C}$ for $30 \mathrm{~s}$, annealing at $60^{\circ} \mathrm{C}$ for $30 \mathrm{~s}$, extension at $72{ }^{\circ} \mathrm{C}$ for $30 \mathrm{~s}$ and final extension at $72{ }^{\circ} \mathrm{C}$ for 5 min. The PCR products including non-target controls were electrophoresed together on a $1.5 \%$ agarose gel along with $1-\mathrm{kb}$ ladder. The gel was stained with ethidium bromide and the bands were visualized under UV light.

\section{Quantitative real-time polymerase chain reaction ( $q R T-P C R$ )}

DNA samples isolated from T. castaneum, L. serricorne and S. oryzae were amplified using thermal cycler (LightCycler 96; Roche, Penzberg, Germany). qPCR reaction mixture $(20 \mu \mathrm{L})$ contained $10 \mu \mathrm{L}$ fast start essential SYBR Green PCR Master Mix (Roche Diagnostics, GmbH, Indianapolis, IN, USA), $2 \mu \mathrm{L}$ $(0.2 \mu \mathrm{M})$ of each $T$. castaneum specific forward and reverse primers, and $5 \mu \mathrm{L}$ of DNA corresponding to $100 \mathrm{ng} /$ reaction served as a template for the study. The amplification conditions were followed as described by Amin et al. (31). Samples without template DNA were used as negative control and the DNA isolated from the adult red flour beetle was used as a positive control.

\section{Regression analysis for quantification of T. castaneum}

About $5 \mathrm{~g}$ of wheat flour was mixed with DNA isolated from adult $T$. castaneum at a concentration of 200, 100, 50, 25, $12.5,1.25$ and $0.125 \mathrm{ng}$, which was equivalent to $10,5,2.5,1$, 0.1, 0.01 and 0.001 adult insects respectively. The total DNA was then isolated from the infested flour and amplified by qRT-PCR as mentioned previously. Regression analysis was performed for the Ct values obtained from the aforementioned seven different concentrations, and it was repeated six times as individual experiments, obtaining altogether 42 samples. All the experiments were run along with the DNA either from $L$. serricorne or S. oryzae, which served as two negative controls in addition to only wheat DNA.

\section{Analysis of defect action level of insect fragments in wheat flour}

To examine the possibility of application of the developed method in unknown samples, wheat flour was purchased randomly from a commercial store (two samples from a popular brand, viz. Aashirvad, Chennai, India and Naga, Dindigul, India) and a local mill (three samples) located in the city of Thanjavur. The DNA extracted from the wheat flour was subjected to qRT-PCR analysis as described earlier.

\section{Data analysis}

Statistical analysis was performed using GraphPad Prism program, v. 8 (32) and two-tailed $t$-test was carried out for all stages of T. castaneum (egg, larva, pupa and adult). ANOVA served to compare among the groups and values $p<0.05$ were considered statistically significant. The $\mathrm{Ct}$ values obtained from qRT-PCR were inversely proportional to the quantity of original template DNA. In order to obtain a regression for the quantification of insect infestation in wheat 
flour, a regression analysis was performed at $95 \%$ confidence level.

\section{RESULTS AND DISCUSSION}

\section{Primer specificity and multiple sequence alignment}

The main aim of this study was to develop a molecular technique to detect and quantify the presence of red flour beetle in wheat flour. qRT-PCR is a well-known technique based on gene expression for rapid detection and quantification of $T$. castaneum in food samples. The $m t C O I$ gene of $T$. castaneum is used as a target, due to its abundance and availability in the cell as multiple copies (33), thus greater sensitivity can be achieved if it was used as a candidate for identifying infestation. The primer for $\mathrm{mtCO}$ gene was designed using Primer Premiere application with options set in the primer probe design and multiplex PCR mode. Several forward and reverse primers were generated from the program that were sorted for suitability based on the recognition site, the annealing site corresponding to the template sequence, the $t_{\mathrm{m}}$ value (melting temperature), guanine-cytosine (GC) ratio, no primer-dimer formation (self-annealing and self-complementarity) and no possibility of hairpin-loop formation. The primer sequence is 5'-GGGCCCACCACATATTTACCGT-3' complementary to leading strand to serve as forward primer and 5'-GAGTGCCGTGAAGAGTGGCT-3' complementary to lagging strand to serve as reverse primer (Fig. 1a).

As the stored wheat flour is prone to harbouring many pests, it is important to ascertain that the designed primer does not cross-react with $\mathrm{mtCO}$ gene of other storage pests. Hence, a multiple sequence alignment of $\mathrm{mtCO}$ gene from all three major storage pests was carried out, which indicated that the red flour beetle gene shares 75 and $43.4 \%$ homology with S. oryzae (internal feeder) and L. serricorne (external feeder) respectively. It was observed that $T$. castaneum primers could not anneal to mtCOI gene (Fig. 1b) of other major

\begin{tabular}{|c|c|c|c|c|c|}
\hline & 14 & 24 & $5^{4}$ & 24 & 54 \\
\hline TACAT TCTAA & TTCTTCCAGG & ATTTGGCATA & ATCTCCCACA & TTATTAGACA & AGAAAGAGGA \\
\hline AT GTAAGATT & $A A G A A G G T C C$ & TAAACCGTAT & & & \\
\hline 81 & $\pi$ & 21 & 8 & 109 & 111 \\
\hline AAGAAAGAAG & CATTTGGAAC & ACTAGGAATA & ATTTATGCAA & TAATAGCAAT & \\
\hline TTCTTTCTTC & GTAAACCTTG & TGATCCTTAT & & & \\
\hline $1: 1$ & 929 & 924 & 194 & 989 & $\because 1$ \\
\hline GGTTTTGTTG & & CCACATATTT & & & \\
\hline & & & & $A C T$ & \\
\hline 181 & 107 & 201 & mit & 221 & 231 \\
\hline & & & & AT & TT T \\
\hline ATAAAGTGAA & GTCGGTGTTA & TTAATAACGA & CAAGGTTGGC & CTTAATTTTA & AAAATCTACT \\
\hline i4 & is" & 39 & 2 & $m$ & int \\
\hline \multirow{2}{*}{$\begin{array}{l}\text { CTAGCCACTC } \\
\text { GA } \overline{T C G G T G A G}\end{array}$} & TTCACGGCAC & & & & AGCACTAGGA \\
\hline & $\overline{A A G T G \bar{C} \overline{C G T}}$ & AGTTTAATTA & A.TATCGGGAA & GATATTATAC & TCGTGATCCT \\
\hline
\end{tabular}
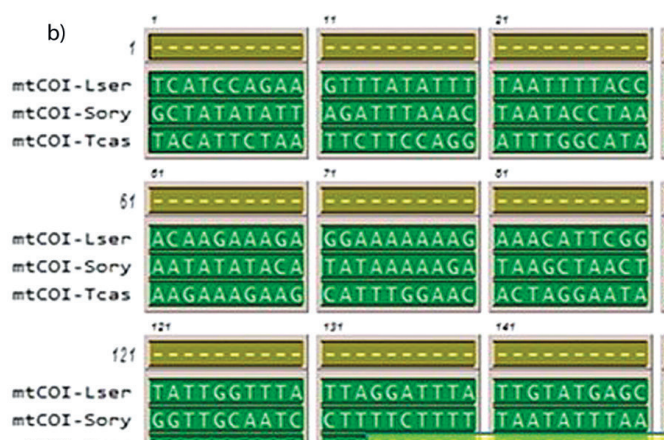

mtCOI-Tcas GGTITTIT<smiles>[SiH3]</smiles>

181

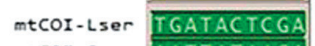

mtCOI-SOry AATTATAAGA

$m$ tCOI-Tcas IATTICACTI

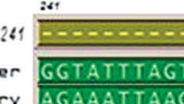

mtCOI-Sory AGAAATIAAC

mtCOI - Tcas
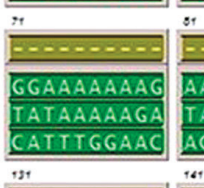

,
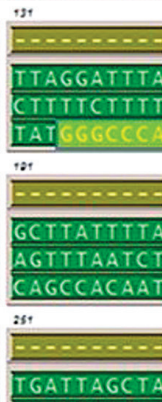

CTTCT TACAC

ITCACGGCAC
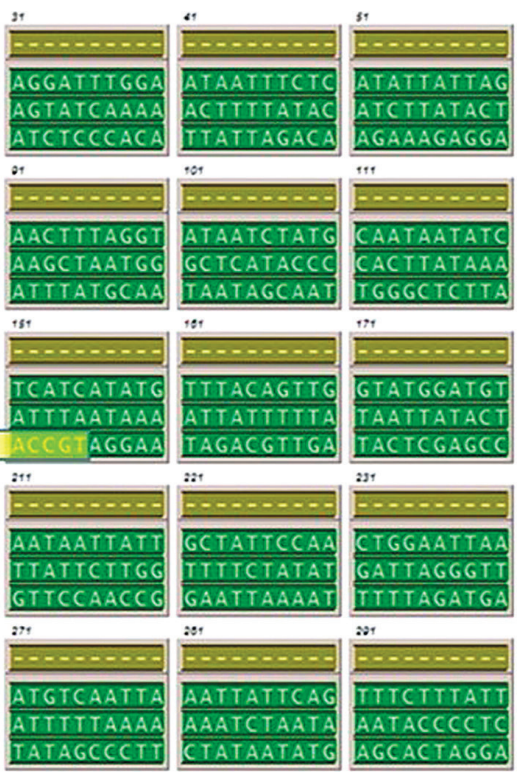

Fig. 1. Multiple sequence alignment of mitochondrial cytochrome oxidase I ( $m+\mathrm{CO} /$ ) gene: a) the gene sequence of Tribolium castaneum mtCOI gene; highlighted is the region of primer binding, and b) alignment of mtCOI sequence from Tribolium castaneum, Lasioderma serricorne and Sitophilus oryzae available in GenBank (26) under accession numbers: EU048277.1, KU494128.1 and NC_030765.1 respectively. The alignment was done by Gene Runner program (27), which shows no similarity in the same gene of other storage pests; highlighted is the forward primer-binding region specific to $T$. castaneum 
pests of wheat flour. Additionally, to reaffirm that the primers do not cross-react with closely related species within the same genus, multiple sequence alignment comparison was made between T. castaneum and T. confusum. The results indicated that the primer is specific only to T. castaneum (Fig. S1) and thus it is proved that $m+C O I$ gene is the ideal candidate for the present study. Elbrecht et al. (34) reported that ideal primer sets with optimal annealing temperatures play a significant role in minimizing the amplification bias among the taxa to maximize species recovery.

\section{Primer specificity and sensitivity}

To analyse the sensitivity of the primer and its ability to detect $T$. castaneum at all ontogenic stages, DNA was purified from egg, larva, pupa and adults that were subjected to PCR amplification (Fig. S2). The results indicated that the sensitivity of the primer is high, that amplification is observed in the DNA samples purified from different ontogenic stages of $T$. castaneum, while no amplification is noticed in the DNA sample from L. serricorne (Fig. 2 and Fig. S3). To increase the stringency level of detection and to avoid false positives, several qRT-PCR assays were performed from the DNA isolated from different sets of samples. The obtained Ct values were tight and a single peak melting curve was observed after every run. In our study, samples with Ct value equal to or above 30, for internal control or samples, were considered negative. The amplification curve appeared in the 12th cycle for pupal stage, in the 15th cycle for egg stage, and the Ct values for larva and adult were in between these two stages (Table 1 and Fig. S4a). The obtained amplification curves appeared as a single bundle, indicating that there was no off-target amplification at any growth stage of $T$. castaneum along the

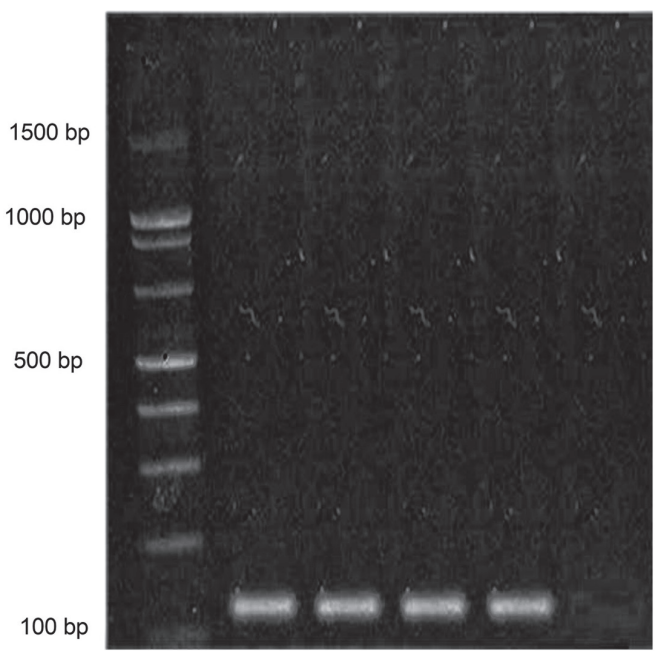

Fig. 2. Electrophoresis of the polymerase chain reaction (PCR) products on $1.5 \%$ agarose gel shows amplification product (128 bp) using primer mitochondrial cytochrome oxidase I (mtCOI). Lane $1=1.5-\mathrm{kb}$ ladder, lane $2=$ Tribolium castaneum adults, lane $3=T$. castaneum pupa, lane $4=T$. castaneum larva, lane $5=T$. castaneum egg, lane $6=L$. serricorne adult as negative control
Table 1. Mean cycle threshold $(\mathrm{Ct})$ values of all ontogenic stages of Tribolium castaneum

\begin{tabular}{ccc} 
T. castaneum & \multicolumn{2}{c}{ Ct value } \\
\cline { 2 - 3 } growth stage & GAPDH & mtCOI \\
Egg & $29.03 \pm 0.03$ & $(15.63 \pm 0.06)^{\mathrm{a}}$ \\
Larva & $24.34 \pm 0.15$ & $(13.12 \pm 0.26)^{\mathrm{b}}$ \\
Pupa & $22.97 \pm 0.23$ & $(12.96 \pm 0.29)^{\mathrm{c}}$ \\
Adult & $26.37 \pm 0.17$ & $14.99 \pm 0.33$
\end{tabular}

Different letters indicate significant differences between the adult and other growth stages at: $\mathrm{a} p<0.01,{ }^{b} p<0.05$, and $\mathrm{c} p<0.01$. Each value is represented as mean \pm S.D. $(N=9)$. GAPDH=glyceraldehyde 3-phosphate dehydrogenase, $m t C O I=$ mitochondrial cytochrome oxidase I

whole run. Melting curve analysis also showed specific melting temperature $\left(t_{\mathrm{m}}\right)$ of $(78.96 \pm 0.09){ }^{\circ} \mathrm{C}$ for all $\mathrm{mtCO}$ amplification products of $T$. castaneum and $(81.4 \pm 0.1){ }^{\circ} \mathrm{C}$ for GAPDH (Fig. S4b). A single sharp peak was observed in the melting curve of control sample and there were no non-specific products and primer dimer observed in the qRT-PCR reaction. Similarly, no amplification or other non-target amplifications were detected in the negative sample, which indicates the specificity of the designed primer used in the study. Previous studies on qPCR data analysis revealed that a single melting curve ensures that the detected signal is genuinely the target of interest (35).

\section{Quantification of T. castaneum infestation by regression analysis}

Serial dilutions of the DNA from adult T. castaneum ranging from 200 to $0.125 \mathrm{ng}$ were mixed with $5 \mathrm{~g}$ of wheat flour. We used $0.125 \mathrm{ng}$ of DNA as the minimum detection level, below which the $\mathrm{Ct}$ values were above 30 , which is considered undetectable or negative, and further loss of linearity was also observed (Table 2, Fig. 3a and Fig. 3b). To increase the reproducibility of the obtained results in each qRT-PCR run, $200 \mathrm{ng}$ of adult T. castaneum DNA were added as positive control, for which the $\mathrm{Ct}$ value was around 16.8 \pm 0.02 .

Table 2. Cycle threshold ( $\mathrm{Ct}$ ) values obtained for Tribolium castaneum in $5 \mathrm{~g}$ of wheat flour used for regression analysis

$\begin{array}{cccc}\text { Sample } & m(\text { DNA }) / n g & \begin{array}{c}N \text { (insect } \\ \text { equivalent) }\end{array} & \text { Ct value } \\ \text { T. castaneum } & 200 & 10 & (16.8 \pm 0.02)^{\mathrm{a}} \\ \text { adult DNA } & 100 & 5 & (20.0 \pm 0.1)^{\mathrm{a}} \\ \text { diluted with } & 50 & 2.5 & (21.67 \pm 0.09)^{\mathrm{a}} \\ \text { wheat DNA } & 25 & 1 & (22.7 \pm 0.2)^{\mathrm{a}} \\ & 12.5 & 0.1 & (27.0 \pm 0.2)^{\mathrm{a}} \\ & 1.25 & 0.01 & (27.9 \pm 0.3)^{\mathrm{a}} \\ & 0.125 & 0.001 & (28.84 \pm 0.08)^{\mathrm{a}} \\ \text { Wheat DNA } & 108 & \text { NA } & 34.4 \pm 1.2\end{array}$

aSignificant difference between all Tribolium DNA mass and wheat DNA at $p<0.01$ level of significance. Each value is represented as mean \pm S.D. $(N=3) . N A=$ not available 


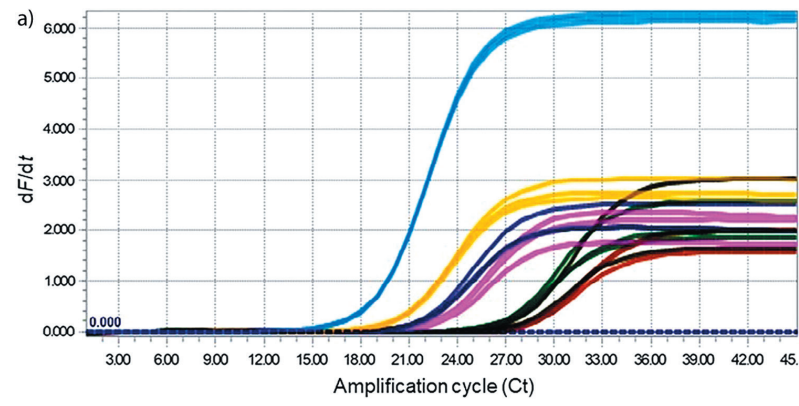

b)

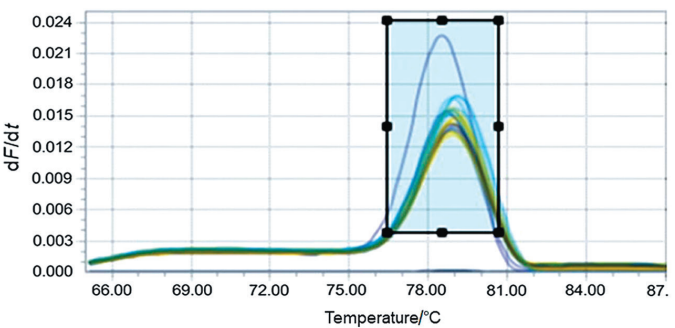

c)

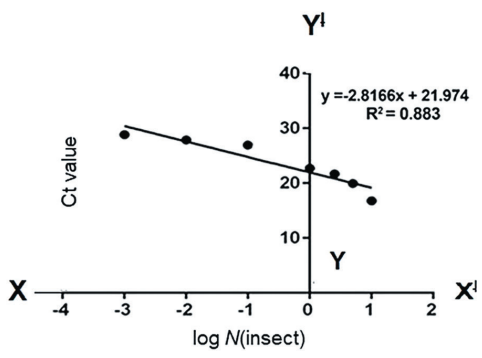

Fig. 3. Quantification of Tribolium castaneum infestation by regression analysis and authenticity of $T$. castaneum detection in infested wheat flour: a) amplification curves of $T$. castaneum in quantitative real time polymerase chain reaction (qRT-PCR) reaction. Decreasing mass of $T$. castaneum adult DNA (ng) from 200, 100, 50, 25, 12.5, 1.25 to 0.125 by serial dilutions with wheat DNA to emulate number of insects $10,5,2.5,1,0.1,0.01,0.001$ in $5 \mathrm{~g}$ of wheat flour. All the insect samples entered logarithmic phase before 29 cycles of reaction, while the wheat DNA used as negative control entered after 33 cycles of amplification, b) melting curve analysis of all serially diluted $T$. castaneum DNA shows positive single peak for $T$. castaneum $\mathrm{mtCOI}$ at $(78.96 \pm 0.09){ }^{\circ} \mathrm{C}$, and c) regression plot for T. castaneum adult DNA shows significant correlation between the log number of insects and cycles threshold $(\mathrm{Ct})$ values in $5 \mathrm{~g}$ of wheat flour $\left(\mathrm{p}<0.0016\right.$ and $\left.\mathrm{R}^{2}=0.883\right) .(-\mathrm{d} / \mathrm{d} t)=$ negative derivative of fluorescence over temperature

As T. castaneum may be detected in the DNA isolated from infested wheat flour, the exact quantity of the insect DNA present in the total DNA might vary with samples. Our data indicated that a minute quantity of insect DNA is sufficient to observe the amplification. The observed $\mathrm{Ct}$ values were so tight $( \pm 1 \mathrm{Ct}$ ) for each stage of the insect, which signifies the conformity of the developed method. Statistical analysis of inter-stage comparison showed a significant change in the expression of $m t C O I$ gene between all stages of the insect growth except for larva and pupa. We presume that there may be fewer developmental changes during the larval and pupal stages, which may be a factor that no significant change in the expression of $\mathrm{mtCOI}$ (36) was observed.
A standard curve was generated by using different mass of $T$. castaneum DNA for quantitative analysis in the wheat flour. Regression analysis revealed statistically significant relation between the DNA mass (mass/infestation dose) and the obtained $C t$ values ( $p<0.0016$ and $R^{2}=0.883$ ) (Fig. $3 c$ ). There was an inverse correlation (described below by the equation for a slope) between the infestation and the Ct values; as the rate of infestation decreased, the $\mathrm{Ct}$ values increased:

$$
y=m x+c
$$

where $y$ stands for $C t$ value from adult insect, $x$ represents the insect infestation dose in wheat flour, and $c$ is a constant. The details of the statistical analysis are presented in Table S1.

$$
\begin{gathered}
y=2.817 x+21.97 \\
R^{2}=0.883
\end{gathered}
$$

Here $\mathrm{R}^{2}$ is a goodness-of-fit measure for linear regression models. The regression line was plotted using $\mathrm{Ct}$ values, which transform correspondingly into the adult equivalents by using Eq. 2. It is understood that the mass of DNA directly correlates with the biomass of the insect, so this technique can be used for quantifying the infestation level present in wheat flour. As reported earlier, the mean fresh mass of adult T. castaneum is about $(2.40 \pm 0.03) \mathrm{mg}$, of larva and pupa $(2.30 \pm 0.06) \mathrm{mg}$ and egg about $(0.0052 \pm 0.0008) \mathrm{mg}$ (37). Our data indicate that $20 \mu \mathrm{g}$ of DNA directly corresponds to $2.2 \mathrm{mg}$ fresh body mass of T. castaneum. Based on the generated regression curve, the $\mathrm{Ct}$ values approached 17, which represents approx. 10 adults present in $5 \mathrm{~g}$ wheat flour. Similarly, the $\mathrm{Ct}$ value near 28 represents 0.001 adult (Table S2). Thus, the inverse prediction of the $\mathrm{Ct}$ values will help in detection and quantification of $T$. castaneum infestation in stored wheat flour, and help in most of the management decisions to safeguard the product. By using a regression curve, it is possible to determine the minimal defect action level of insect fragments present in unknown samples. Our studies are in line with the results reported for Rhyzopertha dominica infestation in rice (38).

Other confounding factors such as high gluten content and polysaccharides present in the wheat flour pose an impediment in the amplification of DNA by interfering with the activity of Taq polymerase in $\mathrm{PCR}$ reaction $(39,40)$. Our results suggested that these factors did not significantly affect the qRT-PCR assay. The smallest level of infestation that can be detected by our method is 1 insect fragment in $5 \mathrm{~kg}$ of flour, which is much lower than the permissible level allowed in countries like the USA and Canada as per the recommendation for minimum defect action level by FDA and CFIA (10).

\section{Authenticity of T. castaneum detection in the infested wheat flour}

To determine the reliability of the developed method, a known number of fragments from T. castaneum were blended with a certain amount of wheat flour. The presence of fragments in the flour was confirmed by staining according to the protocol described in AACC Method 28-41.03 (24) (Fig. S5). 
Then, whole DNA was extracted from the flour containing the fragments and subjected to qRT-PCR analysis. The results indicated that the developed method is sensitive enough to detect the presence of insect infestation at the level of one fragment in $5 \mathrm{~g}$ of wheat flour and the $\mathrm{Ct}$ value was (29.03 \pm 0.04). The number of fragments present in the wheat flour is inversely proportional to the $\mathrm{Ct}$ values obtained from the experiment. In our experiment the $\mathrm{Ct}$ values 27.32, 24.27 and 13.25 indicated the presence of 2,5 and 10 insect fragments in $5 \mathrm{~g}$ of wheat flour respectively. Our study clearly showed that this method is highly sensitive and able to detect one insect fragment in $5 \mathrm{~g}$ of wheat flour (Table 3 and Fig. 4a).

Table 3. Cycle threshold (Ct) values for different Tribolium castaneum threshold samples

\begin{tabular}{lc} 
Sample & Ct value \\
T. castaneum Std. (adult DNA) & $18.4 \pm 0.1$ \\
T1 (1 insect fragment) & $29.03 \pm 0.04$ \\
T2 (2 insect fragments) & $27.3 \pm 0.4$ \\
T3 (5 insect fragments) & $24.3 \pm 0.3$ \\
T4 (10 insect fragments) & $13.2 \pm 0.4$ \\
\hline
\end{tabular}

Each value is represented as mean \pm S.D. $(N=3)$

The developed method was challenged by testing five different blind samples, which were purchased from a local mill and a commercial store. The samples procured from the local mill showed positive results for the presence of insect fragment and the Ct values were 22.6, 25.7 and 32.3 (Fig. 4b and Table 4), whereas the Ct values 30.7 and 30.63 were observed for samples belonging to the popular brand. Correspondingly, the $\mathrm{Ct}$ values were translated to infestation levels by substitution in Eq. 2. The infestation level was 1.74 (sample S1) and 0.046 (sample S2) adults per $5 \mathrm{~g}$ of wheat flour, while the rest of the samples exhibited negligible amounts. The amplified product (128 bp) from qPCR run was confirmed by agarose gel electrophoresis. The method demonstrated in this study can be adopted for the identification and/or quantification of $T$. castaneum infestation in different grains and types of flour such as almond, amaranth, barley, buckwheat,

Table 4. Cycle threshold $(\mathrm{Ct})$ values for quantitative real-time polymerase chain reaction (qRT-PCR) with primer specific for Tribolium castaneum in the samples obtained from a local mill and a commercial store

\begin{tabular}{ccc} 
Sample & Ct value & $\begin{array}{c}N \text { (insects as adult equivalent) } \\
\text { per } m \text { (flour) }=5 \mathrm{~g}\end{array}$ \\
S1 & $22.6 \pm 0.2$ & 1.74 \\
S2 & $25.7 \pm 0.0$ & 0.046 \\
S3 & $32.3 \pm 0.3$ & 0.0002 \\
S4 & $30.7 \pm 0.2$ & 0.0007 \\
S5 & $30.63 \pm 0.06$ & 0.0007 \\
\hline
\end{tabular}

Each value is represented as mean \pm S.D., $N=3, S 1-S 3=$ samples of wheat flour from local mills, S4 and S5=samples of wheat flour from local stores

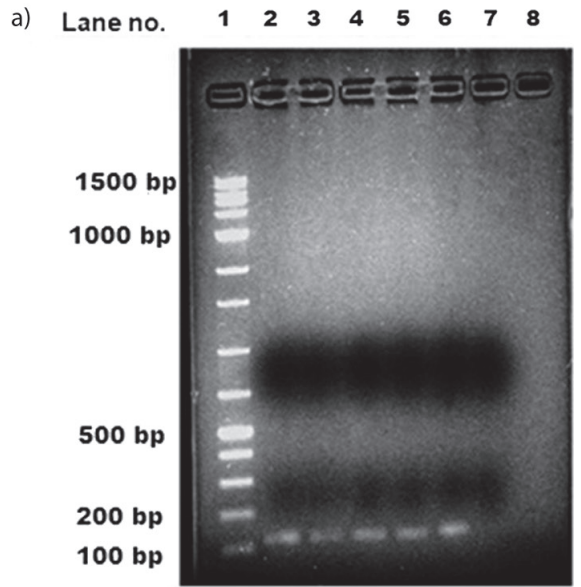

b) Lane no. $\quad \begin{array}{llllllll}\mathbf{1} & 2 & 3 & \mathbf{4} & \mathbf{5} & \mathbf{6} & \mathbf{7} & \mathbf{8}\end{array}$

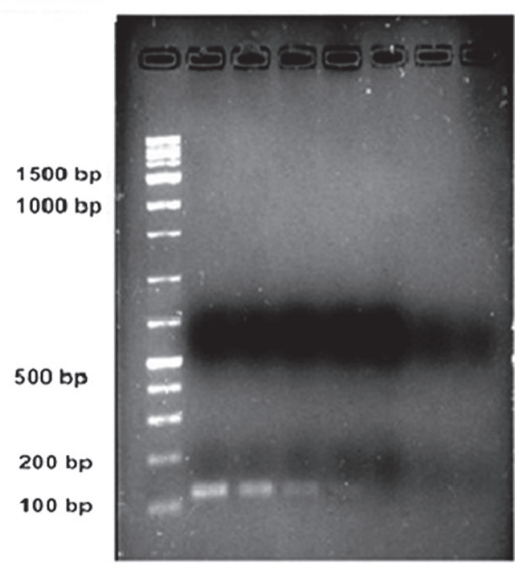

Fig. 4. The results of quantitative polymerase chain reaction (qPCR) analysis show: a) a sequential increase in the amount of amplified mitochondrial cytochrome oxidase I ( $m t C O I$ ) gene corresponding to the mass of insect DNA present in wheat flour. Lane 1=1.5-kb ladder, lane $2=$ amplified product from $T$. castaneum adult DNA (positive control), lane $3=$ wheat flour with one insect fragment, lane $4=$ wheat flour with two insect fragments, lane $5=$ wheat flour with five insect fragments, lane $6=$ wheat flour with ten insect fragments, and lane $7=S$. oryzae adult DNA as negative control, and b) DNA isolated from $5 \mathrm{~g}$ of wheat flour purchased from a commercial store and amplified with mtCOI primer. The qPCR products loaded in lane 1=1-kb ladder, lane $2=$ amplification product from $T$. castaneum DNA (positive control), lane 3=local flour mill sample 1, lane 4=local flour mill sample 2, lane $5=$ local flour mill sample 3, lane $6=$ commercial store flour sample 4, lane $7=$ commercial store flour sample 5 , lane $7=S$. oryzae adult DNA as negative control

cassava, corn, garbanzo, millet, oat, potato, quinoa, rice, rye, sorghum, spelt and coconut (41). Thus, based on our method, it is possible to differentiate between infested and non-infested samples with high sensitivity.

\section{CONCLUSIONS}

The developed qRT-PCR method is highly accurate and species specific that it detects only Tribolium castaneum infestation in a given sample. There were no false positive results obtained when tested against a closely related species 
of the same genus, i.e. T. confusum. Similar results were also obtained when tested with other storage pests such as Sitophilus oryzae and Lasioderma serricorne. To the best of our knowledge, this is the first study to quantify T. castaneum infestation in stored wheat flour using qRT-PCR. Since the method is a rapid technique, it can be adapted in warehouses to effectively manage the pest infestation. Furthermore, governmental agencies responsible for import and export of commodities like wheat flour can use this method to determine if the commodity has infestation below the defect action level. Small sample size will help to analyze more samples from a single batch of stored flour.

\section{ACKNOWLEDGEMENT}

The authors express their sincere gratitude to the Director, Indian Institute of Food Processing Technology, Thanjavur, Tamil Nadu, for providing the technical facilities.

\section{FUNDING}

A.N. wishes to acknowledge the Department of Science and Technology, Government of India for financial support through grant no: DST/WOS-B/2018/1108-HFN (G): Application of molecular based detection techniques for identification and quantification of insect fragments in spices.

\section{CONFLICT OF INTEREST}

All authors of this manuscript declare there is no conflict of interest under financial or personal relationship that could possibly influence the work.

\section{SUPPLEMENTARY MATERIALS}

All supplementary materials are available at www.ftb. com.hr.

\section{AUTHORS' CONTRIBUTION}

A. Negi performed all the experiments, generated data, collected literature and wrote the first draft of the manuscript. A. Anandharaj formulated the concept of the study, designed the experiments, reviewed and analysed the data. S. Kalakandan corrected the manuscript draft. M. Rajamani performed the statistical analysis and supervision of the study. All the authors read and approved the manuscript.

\section{ORCID ID}

A. Negi (1) https://orcid.org/0000-0002-0509-0100

A. Anandharaj (1) https://orcid.org/0000-0002-5888-5273

S. Kalakandan (1) https://orcid.org/0000-0001-9584-772X

M. Rajamani (๑) https://orcid.org/0000-0001-9965-7093

\section{REFERENCES}

1. Ramadas S, Kiran Kumar TM,Singh GP. Wheat production in India: Trends and prospects. In: Shah F, Khan Z, Iqbal A, Turan M Olgun $M$, editors. Recent advances in grain crops research. London, UK: IntechOpen; 2019.

https://doi.org/10.5772/intechopen.86341

2. Nagpal M, Kumar A. Grain losses in India and government policies. Qual Assur Saf Crop Foods. 2012;4(3):143.

https://doi.org/10.1111/j.1757-837X.2012.00150.x

3. Padín S, Dal Bello G, Fabrizio M. Grain loss caused by Tribolium castaneum, Sitophilus oryzae and Acanthoscelides obtectus in stored durum wheat and beans treated with Beauveria bassiana.J Stored Prod Res.2002;38(1):69-74. https://doi.org/10.1016/S0022-474X(00)00046-1

4. Smith Jr LW, Pratt Jr JJ, Nii I, Umina AP. Baking and taste properties of bread made from hard wheat flour infested with species of Tribolium, Tenebrio, Trogoderma and Oryzaephilus. J Stored Prod Res.1971;6(4):307-16.

https://doi.org/10.1016/0022-474X(71)90043-9

5. Devi MB, Devi NV. Biology of rust-red flour beetle, Tribolium castaneum (Herbst) (Tenebrionidae: Coleoptera). Indian J Entomol. 2015;77(1):81-2.

https://doi.org/10.5958/0974-8172.2015.00015.2

6. Perkin LC, Oppert B. Gene expression in Tribolium castaneum life stages: Identifying a species-specific target for pest control applications. Peer J. 2019;7:e6946.

https://doi.org/10.7717/peerj.6946

7. Hodges RJ, Robinson R, Hall DR. Quinone contamination of dehusked rice by Tribolium castaneum (Herbst) (Coleoptera: Tenebrionidae). J Stored Prod Res. 1996;32(1):31-7. https://doi.org/10.1016/0022-474X(95)00036-7

8. El-Mofty MM, Khudoley VV, Sakr SA, Fathala NG. Flour infested with Tribolium castaneum, biscuits made of this flour, and 1,4 benzoquinone induce neoplastic lesions in Swiss albino mice. Nutr Cancer. 1992;17(1):97-104.

https://doi.org/10.1080/01635589209514176

9. Shanmugavel V, Santhi KK, Kurup AH, Kalakandan S, Anandharaj A, Rawson A. Potassium bromate: Effects on bread components, health, environment and method of analysis: A review. Food Chem. 2020;311:125964.

https://doi.org/10.1016/j.foodchem.2019.125964

10. Solà M, Riudavets J, Agustí N. Detection and identification of five common internal grain insect pests by multiplex PCR. Food Control. 2018;84:246-54. https://doi.org/10.1016/j.foodcont.2017.08.002

11. Stejskal V, Hubert J, Aulicky R, Kucerova Z. Overview of present and past and pest-associated risks in stored food and feed products: European perspective. J Stored Prod Res. 2015;64(Part B):122-32.

https://doi.org/10.1016/j.jspr.2014.12.006 
12. Good laboratory practice regulations for nonclinical laboratory studies. In: Code of Federal Regulations (CFR) title 21, chapter I, part 58. Silver Spring, MD, USA: US Food and Drug Administration (FDA); 1988. pp. 229-43.

13. Trematerra P, Stejskal V, Hubert J. The monitoring of semolina contamination by insect fragments using the light filth method in an Italian mill. Food Control. 2011;22(7):1021-6. https://doi.org/10.1016/j.foodcont.2010.11.026

14. Kitto G, Quinn F, Burkholder W. Development of immunoassays for quantitative detection of insects in stored products. In: Wright EJ, Webb MC, Highley E, editors. Proceedings of the Sixth International Working Conference on Stored-Product Protection; 1994 April 17-23. Canberra, Australia; 1994. pp. 415-20.

15. Schatzki TF, Wilson EK, Kitto GB, Behrens P, Heller I. Determination of hidden Sitophilus granarius (Coleoptera: Curculionidae) in wheat by myosin ELISA. J Econ Entomol. 1993;86(5):1584-9.

https://doi.org/10.1093/jee/86.5.1584

16. Perez-Mendoza J, Throne JE, Dowell FE, Baker JE. Detection of insect fragments in wheat flour by near-infrared spectroscopy. J Stored Prod Res. 2003;39(3):305-12. https://doi.org/10.1016/S0022-474X(02)00021-8

17. Hubert J, Nesvorna M, Stejskal V. The efficacy of sieving, filth flotation and Tullgren heat extraction for detecting various developmental stages of Tribolium castaneum and Ephestia kuehniella in samples of wheat grain, flour and semolina. J Stored Prod Res. 2009;45(4):279-88.

https://doi.org/10.1016/j.jspr.2009.05.003

18. Shah MA, Khan AA. Imaging techniques for the detection of stored product pests. Appl Entomol Zool. 2014;49(2):20112.

https://doi.org/10.1007/s13355-014-0254-2

19. Kaliramesh S, Chelladurai V, Jayas DS, Alagusundaram K, White NDG, Fields PG. Detection of infestation by Callosobruchus maculatus in mung bean using near-infrared hyperspectral imaging. J Stored Prod Res. 2013;52:107-11. https://doi.org/10.1016/j.jspr.2012.12.005

20. Karunakaran C, Jayas DS, White NDG. X-ray image analysis to detect infestations caused by insects in grain. Cereal Chem. 2003;80(5):553-7. https://doi.org/10.1094/CCHEM.2003.80.5.553

21. Fornal J, Jeliński T, Sadowska J, Grundas S, Nawrot J, Niewiada $A$, et al. Detection of granary weevil Sitophilus granarius (L.) eggs and internal stages in wheat grain using soft X-ray and image analysis. J Stored Prod Res. 2007;43(2):1428.

https://doi.org/10.1016/j.jspr.2006.02.003

22. Neethirajan S, Karunakaran C, Jayas DS, White NDG. Detection techniques for stored-product insects in grain. Food Control. 2007;18(2):157-62.

https://doi.org/10.1016/j.foodcont.2005.09.008
23. AACC Method 28-44.01. lodine method, for insect eggs in flour. St Paul, MN, USA: American Association of Cereal Chemists (AACC) International; 2000.

24. AACC Method 28-41.03. Acid hydrolysis method for extracting insect fragments and rodent hairs - Light filth in white flour. St Paul, MN, USA: American Association of Cereal Chemists (AACC) International; 2010.

25. Primer Primer 6, PREMIER Biosoft, San Francisco, CA, USA; 2020. Available from: http://www.premierbiosoft.com/ primerdesign/index.html.

26. GenBank. Bethesda, MD, USA: National Center for Biotechnology Information, US National Library of Medicine; 2016. Available from: https://www.ncbi.nlm.nih.gov/genbank.

27. Gene Runner, v. 6.5.52 Beta, Frank Buquicchio and Michael Spruyt; 2019. Available from: http://www.generunner.net.

28. Sang W, He L, Wang XP, Zhu-Salzman K, Lei CL. Evaluation of reference genes for RT-qPCR in Tribolium castaneum (Coleoptera: Tenebrionidae) under UVB stress. Environ Entomol. 2015;44(2):418-25.

https://doi.org/10.1093/ee/nvv010

29. Khammanivong A, Anandharaj A, Qian X, Song JM, Upadhyaya $P$, Balbo $S$, et al. Transcriptome profiling in oral cavity and esophagus tissues from (S)-N'-nitrosonornicotine-treated rats reveals candidate genes involved in human oral cavity and esophageal carcinogenesis. Mol Carcinog. 2016;55(12):2168-82.

https://doi.org/10.1002/mc.22459

30. Anandharaj A, Yu JR, Park WY. Phosphorylation of threonine 190 is essential for nuclear localization and endocytosis of the FTS (fused toes homolog) protein. Int J Biol Macromol. 2011;49(4):721-8.

https://doi.org/10.1016/j.ijbiomac.2011.07.005

31. Amin KN, Umapathy D, Anandharaj A, Ravichandran J, Sasikumar CS, Chandra SKR, et al. miR-23c regulates wound healing by targeting stromal cell-derived factor-1a (SDF1a/CXCL12) among patients with diabetic foot ulcer. Microvasc Res. 2020;127:103924.

https://doi.org/10.1016/j.mvr.2019.103924

32. GraphPad Prism, v. 8, GraphPad Software, San Diego, CA, USA; 2016. Available from: https://www.graphpad.com/ company/.

33. Obrepalska-Steplowska A, Nowaczyk K, Holysz M, Gawlak $M$, Nawrot J. Molecular techniques for the detection of granary weevil (Sitophilus granarius L.) in wheat and flour. Food Addit Contam Part A Chem Anal Control Expo Risk Assess. 2008;25(10):1179-88.

https://doi.org/10.1080/02652030802015689

34. Elbrecht V, Braukmann TWA, Ivanova NV, Prosser SWJ, Hajibabaei M, Wright M, et al.: Validation of COI metabarcoding primers for terrestrial arthropods. Peer J. 2019;7:e7745. https://doi.org/10.7717/peerj.7745 
35. Adams G. A beginner's guide to RT-PCR, qPCR and RT-qPCR. Biochemist. 2020;42(3):48-53. https://doi.org/10.1042/BIO20200034

36. Li H, Zhang H, Guan R, Miao X. Identification of diffential expression genes associatedwith host selection and adaptation between two sibling insect species by transcriptional profile analysis. BMC Genomics. 2013;14:582.

https://doi.org/10.1186/1471-2164-14-582

37. Arnaud L, Brostaux Y, Lallemand S, Haubruge E. Reproductive strategies of Tribolium flour beetles. J Insect Sci. 2005; 5(1):33.

https://doi.org/10.1093/jis/5.1.33

38. Solà M, Lundgren JG, Agustí N, Riudavets J. Detection and quantification of the insect pest Rhyzopertha dominica (F.)
(Coleoptera: Bostrichidae) in rice by qPCR. J Stored Prod Res. 2017;71:106-11.

https://doi.org/10.1016/j.jspr.2017.02.002

39. Fang G, Hammar S, Grumet R. A quick and inexpensive method for removing polysaccharides from plant genomic DNA. Biotechniques. 1992;13(1):52-4.

40. Schlink K, Reski R. Preparing high-quality DNA from moss (Physcomitrella patens). Plant Mol Biol Rep. 2002;20:423a-f. https://doi.org/10.1007/BF02772133

41. Gerken AR, Campbell JF. Oviposition and development of Tribolium castaneum Herbst (Coleoptera: Tenebrionidae) on different types of flour. Agronomy. 2020;10(10):1593. https://doi.org/10.3390/agronomy10101593 